\title{
Characteristics and Sensitivity Analysis Division of Flood Disaster in Hohhot
}

\author{
Zhana $^{1}$, Buren ${ }^{2}$, Fuying Qin ${ }^{3}$
}

1School of Geographical, Inner Mongolia Normal University, Hohhot 010022, China

2School of Geographical, Natural Disaster Prevention Research Institute, Inner Mongolia Normal

University, Hohhot 010022, China

3Inner Mongolia Key Laboratory of Remote Sensing and Geography Information System, Hohhot 010022,

China

\section{呼和浩特市暴雨洪港灾害特征分析及敏感性区划 扎娜 ${ }^{1}$, 布仁 ${ }^{2}$, 秦福荣 ${ }^{3}$ \\ 1 内蒙古师范大学地理科学学院, 呼和浩特 010022 , 中国 \\ 2 内蒙古师范大学地理科学学院, 内蒙古师范大学自然灾害防治研究所, 呼和浩特 010022 , 中国 3 内蒙古自治区遥感与地理信息系统重点实验室, 呼和浩特 010022 , 中国}

\begin{abstract}
Based on 1993 to 2012 of daily precipitation data from seven meteorological station in Hohhot, rainstorm and flood disaster data, Hohhot water distribution figure, 30 meters DEM digital elevation image and Landsat TM images data, using GIS spatial analysis method, classification method, Dimidiate Pixel Model and mathematical statistic method and so on.The influencing factors of the occurrence of rainstorm and flood disaster in Hohhot area were analyzed,and draw the Hohhot regional flood disaster sensitivity zoning map.Results show:High occurrence area and the sub - high occurrence area of rainstorm and flood disaster in Hohhot,the located southeast of Hohhot City,eastern part of He Lin Ge Er County,east of the Qing Shui He county and midwest of Tu Mo Te Zuo Qi.But low occurrence area located on north of Wu Chuan Country.
\end{abstract}

key words: Rainstorm and flood; Cause analysis; Hohhot

摘要

基于呼和浩特地区 7 个气象站 1993 年至
2012 年的逐日降水量数据、暴雨洪涝灾情数据、 呼和浩特水系分布图、30 米 DEM 数字高程影像 以及 Landsat-TM 影像等数据, 运用 GIS 空间分 析法、重分类法、像元二分法以及数理统计方法 等方法, 对呼和浩特地区暴雨洪涝灾害发生的影 响因素进行深入分析, 并绘制出呼和浩特地区暴 雨洪涝灾害敏感性区划图。结果表明: 呼和浩特 地区暴雨洪涝灾害高发生区及次高发生区位于 呼和浩特市区东南部、和林格尔县东部、清水县 东部和土默特左旗中西部; 低发生区位于武川县 北部。

关键词: 暴雨洪涝; 成因分析; 呼和浩特

1. 引言

呼和浩特属典型的蒙古高原大陆性气候, 四 季气候变化明显, 年温差大, 日温差也大。春季 干燥多风, 冷暖变化剧烈; 夏季短暂、炎热、少 雨; 秋季降温迅速, 常有霜冻; 冬季漫长、严寒、 少雪是该地区的主要气候特点。但是该地区降雨 集中, 变率大, 时有雨急量大的超长暴雨发生。 并由于该地区地形起伏较大、植被覆盖度较低、 地表裸露, 一旦发生暴雨或大暴雨, 在暴雨和强 降水的冲刷下, 形成泥石流以及洪涝灾害。

洪涝灾害是一种自然灾害,一般包括洪灾和 涝灾两种。洪灾一般是指河流上游的降水的降雨 


\section{Risk Analysis and Crisis Response in Big Data Era (RAC-16)}

量或降雨强度过大、急骤融冰化雪或水库垮坝等 导致的河流突然水位上涨和径流量增大, 超过河 道正常行水能力, 在短时间内排泄不畅, 或暴雨 引起山洪暴发、河流暴涨漫溢或堤防溃决, 形成 洪水泛滥造成的灾害; 涝灾一般是指本地降雨过 多, 或受沥水、上游洪水的侵袭, 河道排水能力 降低、排水动力不足或受大江大河洪水、海潮顶 托, 不能及时向外排泄, 造成地表积水而形成的 灾害, 多表现为地面受淹, 农作物歉收 ${ }^{[1]}$ 。关于 洪涝灾害风险方面的研究成果较多 ${ }^{[2-4: 11-22]}$, 主要 是从致灾因子、风险预报以及灾后评估等方面进 行研究, 但从致灾因子危险性和孕灾环境敏感性 之间相互作用方面进行的研究较少。呼和浩特地 区有关暴雨洪涝灾害的研究是从暴雨发生频次 和范围等致灾因子方面进行研究, 本文在此基础 上从地形因子、河网密度、土地利用类型和植被 覆盖度等孕灾环境敏感性方面进行研究。基于 此, 本文通过以上五个影响因素的分析对呼和浩 特地区暴雨洪涝灾害风险区域进行等级划分, 为 以后进行暴雨洪涝灾害防御提供有效的理论依 据。

\section{2. 资料与研究方法}

\section{1 资料}

本文选取呼和浩特地区 7 个气象站 1993 年 至 2012 年的逐日降水量、暴雨洪涝灾情数据、 呼和浩特市水系分布图、30 米的 DEM 数字高程 影像以及 Landsat-TM 影像等数据和历史灾情资 料。

\section{2 研究方法}

\subsection{1 致灾因子分析}

本文将运用数理统计方法对呼和浩特地区 1993 年至 2012 年 20 年的逐日降水资料进行分 析, 得到呼和浩特地区暴雨的时间分布特征和地 理分布特征并依据通常的降雨量强度分类标准, 按照日降雨量分为暴雨和大暴雨两种, 无特大暴 雨, 日降雨量 (日界为北京时间 08 时一次日 08 时) 在 $50.0 \mathrm{~mm}-99.9 \mathrm{~mm}$ 为暴雨、日降雨量在 100. $0 \mathrm{~mm}-199.9 \mathrm{~mm}$ 为大暴雨。

\subsection{2 孕灾环境}

孕灾环境是指由大气圈、岩石圈、水圈、生 物圈所组成的综合地球表层环境以及在此环境 中的一系列物质循环、能量流动以及信息与价值 流动的过程与响应关系。地球表层的孕灾环境对 灾害系统的复杂程度、灾情强度以及灾害系统的 群聚与群发特征起着决定性的作用 ${ }^{[5]}$ 。本文孕灾 环境主要从该地区土地利用类型、地形、植被覆 盖度以及河网密度进行分析。植被覆盖度运用像 元二分法在呼和浩特地区 Landsat-TM 影响的基 础上进行, 将呼和浩特地区由低到高分五个等 级; 地形因子采用 30 米的 DEM 数字高程影像在 GIS 中做重分类, 将呼和浩特地形由低到高分五 个等级; 河网密度采用呼和浩特地区水系分布图 在 GIS 空间分析中做水文分析, 得到呼和浩特河 网密度分布图。

\section{3. 结果分析}

\section{1 暴雨时空特征}

呼和浩特在 1993 年至 2012 年 20 年间共发 生了 42 次暴雨, 平均每年 2.1 次。大暴雨较少, 共发生了 4 次, 平均每年 0.1 次, 无特大暴雨发 生。其中暴雨发生偏多的年份为 1995、1998、 2008 和 2012 , 占总数 $52.4 \%$, 其余年份发生次 数较少, 4 次大暴雨分别发生在 1995 年和 1998 年均为 2 次 (图 1)。呼和浩特地区主要降水时 间在 5 月- - 10 月之间, 占全年降水量的 $82 \%$, 其中 6 月-9 月的降水量较集中, 占全年降水量 的 73\%。从图中的暴雨频次曲线来看, 暴雨均发 生在 6 月- 8 月之间, 其余月份无暴雨发生记录。 主要 7 月和 8 月发生暴雨次数多, 分别为 25 次 和 7 次, 占总数的 $60 \%$ 和 $16 \% ; 6$ 月和 9 月分别 发生了 5 次, 分别占总数的 $12 \%$, 大暴雨均发生 在 7 月。

根据呼和浩特每个气象站 42 年的暴雨资料 统计, 和林格尔县和土默特左旗为最多, 分别发 生了 8 次; 北部的武川县最少, 共 3 次 (图 2)。 
Risk Analysis and Crisis Response in Big Data Era (RAC-16)

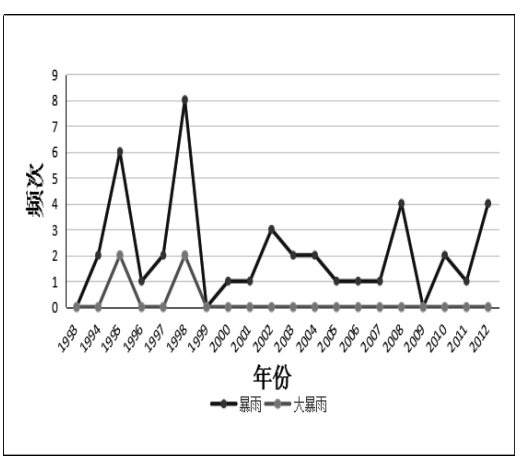

图 1 呼和浩特暴雨频次历史曲线图

Fig1 History diagram of the frequency of heavy rain in Hohhot

\section{2 洪涝灾害发生的影响因素}

\subsection{1 降水分布特征}

降水量指降落在地面的雨和融化后的雪、

雹、霰等未经蒸发、渗透和流失, 积聚在水平面 上的水层厚度, 以毫米 $(\mathrm{mm})$ 为单位, 取小数一位。 气象站、水文观测站用雨量筒和雨量计来测定降 水量 ${ }^{[6]}$ 。根据 1993 年至 2012 年逐日降水量数据 的平均值, 运用样条函数法在 GIS 中进行空间插 值, 得到了呼和浩特地区降水分布图（图 3)。 降水量多的地区要比降水量少的地区发生洪涝 灾害的机率要大一些。从图 3 中可看出, 呼和浩 特南部的清水河县和东部的和林格尔县、呼和浩 特市南部以及土默特左旗东南部的降水最多, 呼 和浩特北部的武川县的降水最少, 其余地区降水 适中。

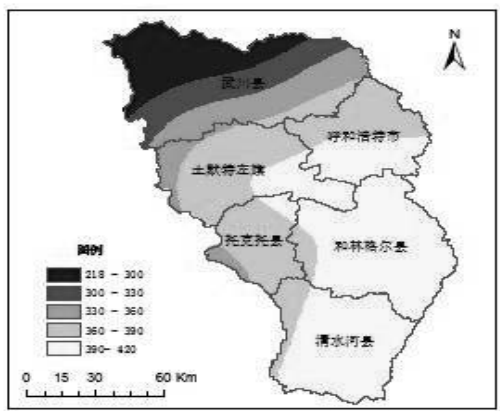

图 3 呼和浩特降水分布图

Fig3 Distribution map of precipitation in Hohhot

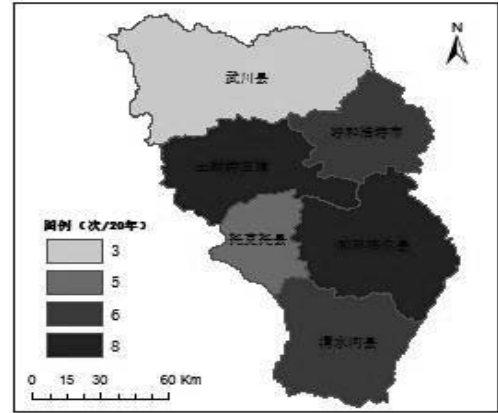

图 2 呼和浩特地区暴雨分布图

Fig2 Distribution map of Rainstorm in Hohhot

\subsection{2 地形因子的影响}

地形与暴雨洪涝发生的危险性关系紧密, 地 形对形成洪水的影响主要表现在地形高程及地 形变化程度两个方面 ${ }^{[7]}$, 地形高程越高、变化越 大则表明地势起伏较大, 越容易发生洪涝灾害; 反之, 地形高程越低、变化越小则表明地势较为 平坦, 不容易发生洪涝灾害。通过对 30 米 DEM 数字高程影像的处理, 得到呼和浩特地形分布图 (图 4)。从图 4 中可得, 呼和浩特北部的武川 县地形虽高, 但地形变化较小, 所以地形起伏较 小以及呼和浩特中部的托克托县地形地、变化 小, 所以地形平坦, 因此武川县和托克托县发生 洪涝灾害的机率小; 反之, 土默特左旗、呼和浩 特市区以及和林格尔县地形变化较大, 地面起伏 不平, 所发生洪涝灾害的机率大。

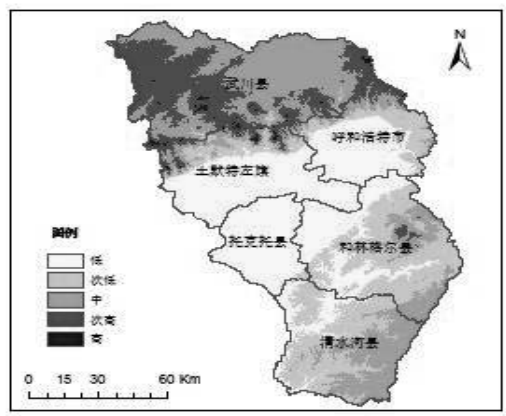

图 4 呼和浩特地形分布图

Fig4 Topographic map of Hohhot 


\section{Risk Analysis and Crisis Response in Big Data Era (RAC-16)}

\subsection{3 植被覆盖度的影响}

植被覆盖度是一定范围内林地（林地和草 地）面积与区域土地面积的百分比, 表示某一区 域的植被分布状况。在洪涝发生时, 同等情况下 植被覆盖度越低, 对洪水的延阻能力就越小, 洪 水的危险性就越高, 因此植被覆盖度是洪涝灾害 孕灾环境的重要指标之一 ${ }^{[8]}$ 。本文在 Landsat-TM 影响的基础上, 运用像元二分模型法, 在常用的 植被指数 NDVI 的基础上求出植被覆盖度并对此 用重分类方法按植被覆盖率均等分五个等级 (图 5)。从图中可看出, 土默特左旗、托克托县以 及呼和浩特市区植被覆盖度较高, 反而清水河县 植被覆盖度较低, 其余地方的植被覆盖度为适 中。

\subsection{4 河网密度的影响}

河网密度是单位面积内的河流长度, 一定 程度上可以反映出下垫面产流条件的空间比变

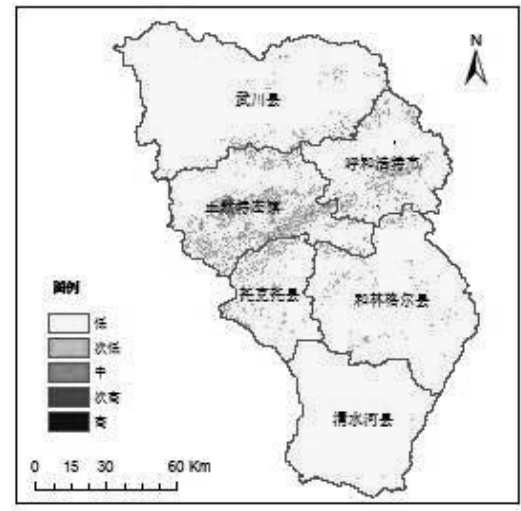

图 5 呼和浩特植被覆盖度分布图

Fig5 Distribution map of vegetation coverage in Hohhot

\section{4. 暴雨洪涝灾害敏感性区划}

通过 GIS 空间分析能力, 在呼和浩特地区 暴雨分布图、地形分布图、河网密度分布图和植 被覆盖度分布图及降水分布图的基础上, 利用孕 灾环境敏感性指数 $E=W_{\mathrm{E} 1} \cdot X_{\mathrm{E} 1}+W_{\mathrm{E} 2} \cdot X_{\mathrm{E} 2}+W_{\mathrm{E} 3} \cdot X_{\mathrm{E} 3}+W_{\mathrm{E} 4}$ $\cdot X_{E 4}+\left(1-W_{E 5}\right) \cdot X_{E 5}$, 得到呼和浩特地区暴雨洪涝灾 害敏感性区划图（图 7)。呼和浩特地区暴雨洪 涝灾害高发生区位于和林格尔县和清水河县东 部地区; 次高区位于呼和浩特市东南部、和林格 尔县中部、清水河县中东部以及土默特左旗中西
化, 河网的分布在很大程度上决定了区域遭受洪 水侵袭的难易程度 ${ }^{[9]}$ 。本文对呼和浩特水文地图 进行扫描矢量化, 在此基础上, 在 GIS 中对呼和 浩特地区水系分布图进行网格建立并计算每个 网格内的河流长度和面积之比, 由此得到河流密 度, 最后在 GIS 中做区域密度分析, 得到呼和浩 特河流分布图 (图 6)。主要考虑河网密度河网 越密集的地方, 暴雨季节就越容易蓄洪产洪, 因 此遭受洪涝灾害的风险越大, 河网密度稀疏的地 方洪涝发生的风险相对就小。图 6 中可看出, 呼 和浩特地区的武川县南部、土默特左旗南部、呼 和浩特市区北部、和林格尔县南部以及清水河县 北部河流密度高, 这就表明这些地区比别的河流 密度低的地方容易发生洪涝灾害。

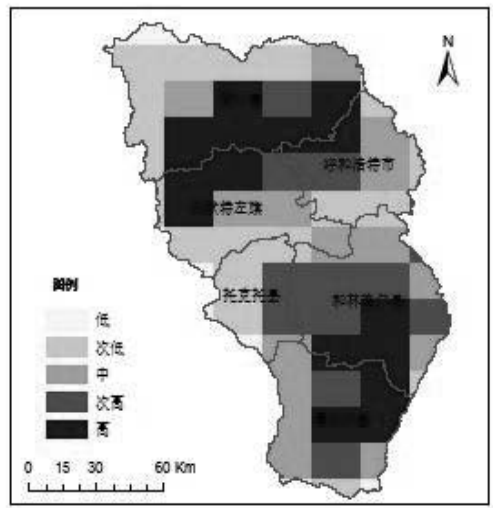

图 6 呼和浩特河网密度分布图

Fig6 Density distribution of river network in Hohhot 部; 低发生区位于武川县北部。其原因在于和林 格尔县和清水河县降水量较多、暴雨发生次数 多、地面起伏较大、植被覆盖度较低以及河网密 度较高, 而武川县北部暴雨发生次数少、地面起 伏较小、远离高河网密度区, 所以成为了暴雨洪 涝灾害发生最低区。

\section{5. 结果检验}

通过对呼和浩特地区洪涝灾害历史资料进 行分析, 依据历年呼和浩特地区发生的洪涝灾害 频次进行区分, 得到呼和浩特地区洪涝灾害频次 
Risk Analysis and Crisis Response in Big Data Era (RAC-16)

分布图（图 8)。并通过与图 7 的对比, 两个图 基本相似, 这也说明了上述对暴雨频次分布以及

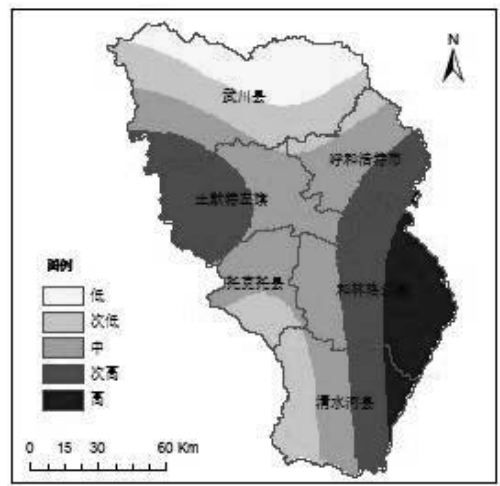

图 7 呼和浩特地区暴雨洪涝敏感性区划图

Fig7 Sensitivity of rainstorm and flood disaster in Hohho

\section{6. 结论与讨论}

(1) 呼和浩特地区主要降水时间在 5 月- 10 月之间，占全年降水量的 $82 \%$, 其中 6 月- 9 月 的降水量较集中, 占全年降水量的 $73 \%$ 。呼和浩 特的暴雨均发生在 6 月- 8 月之间, 其余月份无 暴雨发生记录。其中 7 月和 8 月发生暴雨次数多, 分别为 25 次和 7 次，占总数的 $60 \%$ 和 $16 \% ; 6$ 月 和 9 月分别发生了 5 次, 分别占总数的 $12 \%$, 大 暴雨均发生在 7 月。

(2)呼和浩特降水的地理分布特征为呼和浩 特南部的清水河县和东部的和林格尔县、呼和浩 特市南部以及土默特左旗东南部的降水最多, 呼 和浩特北部的武川县的降水最少。暴雨发生最多 的地方为和林格尔县和土默特左旗, 共 16 次; 最少的是北部的武川县, 共 3 次。

据分析, 地形因子、植被覆盖度、河网密 集程度以及降水量等因素对发生洪涝灾害有密 切的影响。呼和浩特地区暴雨洪涝灾害高发生区 及次高发生区位于呼和浩特市区东南部、和林格 尔县东部、清水县东部和土默特左旗中西部; 反 之低发生区位于武川县北部。

（3）由于暴雨洪涝灾害发生机理研究较 难, 影响因素较多, 所以进行全面完整的分析研 究存在一定的困难。本文在以前研究者所提出的 观点的基础上, 进一步从降水量、地形因子、植
暴雨洪涝灾害发生的敏感性因素研究是符合实 际的, 是切实可行的。

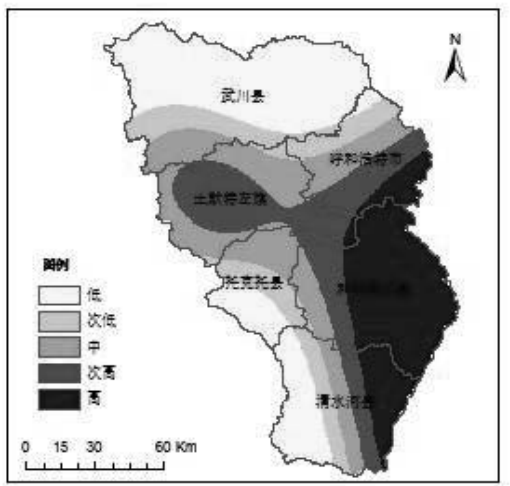

图 8 呼和浩特地区洪涝灾害频次分布图 Fig8 Frequency distribution of flood disasters in Hohhot 被覆盖度及河网密度等影响因素方面进行了研 究, 并通过赋予不同的权重系数, 得到了呼和浩 特地区暴雨洪涝灾害敏感性区划图且与实际情 况基本相符, 因此可用性很强, 可以为今后的研 究提供有效依据。

\section{致谢}

本研究得到了基于 $3 \mathrm{~S}$ 技术的城镇暴雨洪水灾害 风险评估与应急管理关键技术研究项目资助 （201502095）。

作者简介: 扎娜 (1992-) , 女, 内蒙古鄂尔多 斯人, 硕士研究生, 研究方向: 土地利用规划与 设计。

通讯作者: 布仁 (1964-) , 男, 内蒙古鄂尔多 斯人, 教授, 博士, 研究生导师, 研究方向: 区 域土地利用一土地覆盖变化与环境变迁, burenjiri@163. com。

\section{参考文献}

[1] 丁一汇, 张建云等. 暴雨洪涝, 气象出版 社, 2009.

[2] 周成虎, 万庆, 黄诗峰, 陈德清. 基于 GIS 的 洪水灾害风险区划研究. 地理学报, 2000, 01:15-24.

[3] 张会, 张继权, 韩俊山. 基于 GIS 技术的洪涝 灾害风险评估与区划研究——以辽河中下 游地区为例。自然灾害学报, 2005, $06: 141-146$. 
Risk Analysis and Crisis Response in Big Data Era (RAC-16)

[4] 李军玲, 刘忠阳, 邹春辉. 基于 GIS 的河南省 洪涝灾害风险评估与区划研究. 气象, 2010, 02:87-92.

[5]刘敏. 现代地理科学词典, 科学出版社, 2009

[6]地质出版社. 地球科学大辞典: 基础学科卷, 地质出版社, 2006.

[7]叶金玉. 基于 GIS 的闽江流域洪灾风险分析 与区划研究. 福建师范大学, 2003.

[8]喻莎莎. 山区镇域山洪灾害危险性评价. 重庆 交通大学, 2014.

[9] 暴雨洪涝灾害风险区划技术规范， 2009 .

[10] 赵艳丽. 呼和浩特暴雨成因及诊断分析. 兰 州大学, 2008.

[11] 吴歆彦. 基于 GIS 的呼和浩特市赛罕区气 象灾害风险区划研究. 内蒙古大学, 2014.

[12]李喜仓, 白美兰, 杨晶, 邸瑞琦, 高志国. 基 于 GIS 技术的内蒙古地区暴雨洪涝灾害风 险区划及评估研究. 干旱区资源与环境, 2012, $07: 71-77$.

[13]李楠, 任颖, 顾伟宗, 陈艳春. 基于 GIS 的山 东省暴雨洪涝灾害风险区划。中国农学通 报, 2010, 20:313-317.

[14]P. Chen, J.Q. Zhang, L.F. Zhang, Y.Y. Sun. Research of city rainstorm waterlogging scene simulation -- in Daoli District of Harbin City as an example. Journal of Risk Analysis and Crisis Response, 2015, 5(1): 66-72.

[15]蒋新宇, 范久波, 张继权, 佟志军, 刘兴朋. 基于 GIS 的松花江干流暴雨洪涝灾害风险 评估. 灾害学, 2009, 03:51-56.

[16]刘登峰, 王栋, 王远坤, 王腊春, 邹欣庆. 一 种祸合 Copula-云的城市水灾害风险评价 模型. 风险分析和危机反应中的信息技术, 黄崇福, 包玉海, 赵思健编.巴黎: Atlantis 出版社, 2014. 704-708

[17]莫建飞, 陆甲, 李艳兰, 匡昭敏. 基于 GIS 的 广西农业暴雨洪涝灾害风险评估. 灾害 学, 2012, 01:38-43.

[18]王栋, 潘少明, 吴吉春, 朱庆平. 洪水的风险 分析. 应用基础与工程科学学报, 2004 增 刊, 134-140.

[19] 郭恩亮, 任学慧, 张炎. 辽宁沿海城市暴雨 洪涝灾害风险评价风险分析和危机反应的 创新理论和方法, 黄崇福, 翟国方编.巴黎: Atlantis 出版社, 2012. 103-108.
[20]王菜林, 任学慧. 基于极端降水事件的辽宁 省暴雨标准及其空间分布. 风险分析和危 机反应中的信息技术, 黄崇福, 包玉海, 赵思健编.巴黎: Atlantis 出版社, 2014. 96-101.

[21] 郭恩亮, 张继权, 孙仲益, 乌兰, 朱萌. 农业 洪涝灾害风险评价研究综述. 风险分析和 危机反应中的信息技术, 黄崇福, 包玉海, 赵思健编.巴黎: Atlantis 出版社, 2014. 613-818

[22]W. Zhang, Y.J. Hu, J.H. Wang, C.Y. Zhang. Research on urban waterlogging disaster risk assessment based on ARCGIS and MIKE FLOOD - A Case Study on Shijiazhuang. Journal of Risk Analysis and Crisis Response, 2015, 5(4): 226-233. 